\title{
Badanie stabilności termooksydacyjnej smarów plastycznych. Część 2: Smary na oleju o charakterze naftenowym
}

\begin{abstract}
W artykule przedstawiono wyniki badań laboratoryjnych odporności na utlenianie smarów litowych i polimocznikowych, wytworzonych na bazie oleju o charakterze naftenowym, z zastosowaniem dodatków przeciwutleniających o różnej strukturze chemicznej. Badanie odporności na utlenianie prowadzono według metody PN-C-04143:1956 przeznaczonej dla smarów oraz przy użyciu zmodyfikowanej metody Petrooxy.
\end{abstract}

Słowa kluczowe: smary, inhibitory utlenienia, odporność na utlenianie.

\section{Determination of thermal-oxidation stability of lubricating greases. Part 2: Greases based on naftenic base oil}

The article presents the results of laboratory tests of the oxidation stability of lithium greases and polyurea greases manufactured on the basis of naftenic oils, with the use of antioxidants characterized by a different chemical structure. Oxidation stability was carried out in accordance with the PN-C-04143:1956 method which is dedicated to lubricating greases and with the modified Petrooxy method.

Key words: greases, antioxidants, oxidation stability.

\section{Wprowadzenie}

Artykuł jest kontynuacją rozważań przedstawionych w publikacji pt.: Badanie stabilności termooksydacyjnej smarów plastycznych. Część 1: Smary na oleju o charakterze para- finowym [2], równocześnie nawiązuje on do pracy pt.: $B a-$ danie możliwości modyfikacji stabilności termooksydacyjnej olejów bazowych [1].

\section{Metodyki badawcze}

Badanie odporności smarów na utlenianie prowadzono według następujących metod badawczych:

- PN-C-04143:1956 Przetwory naftowe - Smary state - Badanie odporności na utlenianie. Oznaczenie polega na utlenianiu badanej próbki smaru w ściśle określonych warunkach ciśnienia, temperatury i czasu:

- ciśnienie początkowe: $800 \mathrm{kPa}(0,8 \mathrm{MPa})$,

- temperatura: $100^{\circ} \mathrm{C}$,

- czas: 100 godzin,

- ilość próbki: $10 \mathrm{~g}$ smaru (po $2 \mathrm{~g}$ smaru w pięciu szklanych naczynkach).
Wynik podawany jest jako spadek ciśnienia [MPa] po 100 godzinach utleniania w temperaturze $100^{\circ} \mathrm{C}[3]$;

- PN-EN 16091:2011 Ciekte przetwory naftowe - Paliwa i mieszaniny ze średnich destylatów naftowych i estrów metylowych kwasów tluszczowych (FAME) - Oznaczanie stabilności oksydacyjnej metoda szybkiego utleniania w matej skali. Badanie polega na utlenianiu badanej próbki w ściśle określonych warunkach ciśnienia, temperatury i czasu:

- ciśnienie: $800 \mathrm{kPa}(0,8 \mathrm{MPa})$,

- temperatura: $100^{\circ} \mathrm{C} \mathrm{i} 140^{\circ} \mathrm{C}$,

- ilość próbki: $4 \mathrm{~g}$ smaru w naczynku reakcyjnym. 
Wynik podawany jest jako czas [s] upływający od początku oznaczania do punktu załamania [4].
Metoda ta jest dedykowana do badania paliw silnikowych; dla smarów zmodyfikowano warunki testu.

\section{Próbki do badań}

\section{Surowce}

Surowce zastosowane do wytworzenia próbek smarów:

- olej bazowy o charakterze naftenowym, grupy V według klasyfikacji API,

- zagęszczacze:

- mydło metaliczne: 12-hydroksystearynian litu,

- organiczny: polimocznik;

- inhibitory utleniania najnowszej generacji, typu:
A - fenolowy prosty,

$\mathrm{B}$ - fenolowy rozgałęziony,

$\mathrm{C}$ - aminowy,

D - mieszany fenolowo-aminowy,

E - ZnDTP (dialkiloditiofosforan cynku),

$\mathrm{F}$ - karbaminian.

Właściwości oleju bazowego przedstawiono w tablicy 1, natomiast charakterystykę dodatków zaprezentowano w tablicy 2.

Tablica 1. Właściwości fizykochemiczne oleju bazowego

\begin{tabular}{|l|c|c|}
\hline \multicolumn{1}{|c|}{ Właściwości } & Olej bazowy & Metody badań \\
\hline Lepkość kinematyczna w temperaturze $40^{\circ} \mathrm{C}\left[\mathrm{mm}^{2} / \mathrm{s}\right]$ & 100,2 & PN-EN ISO 3104:2004 \\
\hline Lepkość kinematyczna w temperaturze $100^{\circ} \mathrm{C}\left[\mathrm{mm}^{2} / \mathrm{s}\right]$ & 8,823 & PN-EN ISO 3104:2004 \\
\hline Wskaźnik lepkości & 38 & PN-ISO 2909:2009+Ap1:2010 \\
\hline Barwa & 1,5 & PN-ISO 2049:2010 \\
\hline Temperatura płynięcia $\left[{ }^{\circ} \mathrm{C}\right]$ & -28 & PN-ISO 3016:2005 \\
\hline Zawartość siarki $[\%(\mathrm{~m} / \mathrm{m})]$ & 0,061 & PN-EN 8745:2007+Ap1:2014 \\
\hline Liczba kwasowa $[\mathrm{mg} \mathrm{KOH} / \mathrm{g}]$ & 0,01 & PN-C-04049:1988 \\
\hline Temperatura zapłonu $\left[{ }^{\circ} \mathrm{C}\right]$ & 221 & PN-EN ISO 2592:2008 \\
\hline Skład grupowy węglowodorów $[\%(\mathrm{~m} / \mathrm{m})]$ & 16 & Spektroskopia w podczerwieni \\
$-\mathrm{Ca}$ & 36 & \\
$-\mathrm{Cn}$ & 48 & \\
$-\mathrm{Cp}$ & & \\
\hline
\end{tabular}

Tablica 2. Charakterystyka inhibitorów utleniania

\begin{tabular}{|c|c|c|c|c|c|c|}
\hline Nazwa handlowa & A & B & $\mathrm{C}$ & $\mathrm{D}$ & $\mathrm{E}$ & $\mathrm{F}$ \\
\hline Typ związku chemicznego & fenolowy & fenolowy & aminowy & $\begin{array}{l}\text { mieszany fenolo- } \\
\text { wo-aminowy }\end{array}$ & ZnDTP & karbaminian \\
\hline Związek chemiczny & $\begin{array}{l}\text { 2,6-di-tert- } \\
\text { butyl-p-cresol } \\
\quad \text { (BHT) }\end{array}$ & $\begin{array}{l}2,2^{\prime}, 6,6^{\prime} \text {-tetra- } \\
\text { tertbutyl-4,4'- } \\
\text { methylene di- } \\
\text { phenol }\end{array}$ & $\begin{array}{l}\text { benzenamine, } \\
\text { N-phenyl-, } \\
\text { styrenated, } \\
\text { diphenylamine }\end{array}$ & $\begin{array}{l}\text { bis }(4-(1,1,3,3- \\
\text { tetramethylbutyl) } \\
\text { phenyl) amine, } \\
\text { di-octylated di- } \\
\text { phenylamine }\end{array}$ & $\begin{array}{l}\text { zinc dialkyldi- } \\
\text { thio-phosphate } \\
\text { with primary } \\
\text { alkyl groups }\end{array}$ & $\begin{array}{l}4,4 \text { '-methy- } \\
\text { lene-bis- di- } \\
\text { butyldithio } \\
\text { carbamate }\end{array}$ \\
\hline \multicolumn{7}{|l|}{ Właściwości: } \\
\hline $\begin{array}{l}\text { Wygląd w temperaturze } \\
20 \pm 5^{\circ} \mathrm{C}\end{array}$ & $\begin{array}{c}\text { proszek } \\
\text { barwy białej }\end{array}$ & $\begin{array}{l}\text { proszek barwy } \\
\text { żółtej }\end{array}$ & $\begin{array}{l}\text { ciecz barwy } \\
\text { żółtej }\end{array}$ & $\begin{array}{c}\text { granulki } \\
\text { jasnobrązowe }\end{array}$ & $\begin{array}{l}\text { ciecz barwy } \\
\text { żółtej }\end{array}$ & $\begin{array}{l}\text { ciecz barwy } \\
\text { żółtej }\end{array}$ \\
\hline Temperatura zapłonu $\left[{ }^{\circ} \mathrm{C}\right]$ & 127 & $>170$ & $>230$ & 257 & $>150$ & ok. 220 \\
\hline Temperatura topnienia $\left[{ }^{\circ} \mathrm{C}\right]$ & ok. 69 & 154 & - & 85 & - & - \\
\hline $\begin{array}{l}\text { Gęstość w temperaturze } \\
20^{\circ} \mathrm{C}[\mathrm{g} / \mathrm{ml}]\end{array}$ & 1,030 & - & 1,090 & 0,99 & 1,100 & 1,060 \\
\hline $\begin{array}{l}\text { Lepkość kinematyczna } \\
\text { w temperaturze } 40^{\circ} \mathrm{C} \\
{\left[\mathrm{mm}^{2} / \mathrm{s}\right]}\end{array}$ & - & - & ok. 700 & - & ok. 150 & ok. 360 \\
\hline
\end{tabular}




\section{Sposób wytworzenia próbek do badań}

Smary bazowe ( $\mathrm{N}$ - bez inhibitorów utleniania) oraz smary zawierające dodatki antyutleniające (od A do F) wytwarzano w reaktorze o pojemności $1 \mathrm{~kg}$ i poddawano homogenizacji na młynie korundowym typu Fryma, przy szczelinie $0,2 \mathrm{~mm}$.
Wytworzone smary zawierały jako zagęszczacz jedną z podanych poniżej substancji:

- 12-hydroksystearynian litu, w ilości około 7\%,

- polimocznik, w ilości około $15 \%$.

Właściwości smarów przedstawiono w tablicach 3 i 4.

Tablica 3. Właściwości smarów litowych

\begin{tabular}{|l|c|c|c|c|c|c|c|}
\hline \multicolumn{1}{|c|}{ Numer próbki } & TOLi0 & TOLi1 & TOLi2 & TOLi3 & TOLi4 & TOLi5 & TOLi6 \\
\hline \multicolumn{1}{|c|}{ Rodzaj inhibitora } & N (brak) & A & B & C & D & E & F \\
\hline Właściwości: & 255 & 257 & 259 & 255 & 258 & 255 & 257 \\
\hline Penetracja w temperaturze $25^{\circ} \mathrm{C}$ po ugniataniu 60 razy $[\mathrm{mm} / 10]$ & 194 & 198 & 198 & 197 & 199 & 195 & 193 \\
\hline Temperatura kroplenia $\left[{ }^{\circ} \mathrm{C}\right]$ &
\end{tabular}

Tablica 4. Właściwości smarów polimocznikowych

\begin{tabular}{|l|c|c|c|c|c|c|c|}
\hline \multicolumn{1}{|c|}{ Numer próbki } & TOPu0 & TOPu1 & TOPu2 & TOPu3 & TOPu4 & TOPu5 & TOPu6 \\
\hline \multicolumn{1}{|c|}{ Rodzaj inhibitora } & N (brak) & A & B & C & D & E & F \\
\hline Właściwości: & 275 & 291 & 294 & 298 & 283 & 272 & 279 \\
\hline Penetracja w temperaturze $25^{\circ} \mathrm{C}$ po ugniataniu 60 razy $[\mathrm{mm} / 10]$ & 242 & 242 & 244 & 246 & 247 & 243 & 244 \\
\hline Temperatura kroplenia $\left[{ }^{\circ} \mathrm{C}\right]$ & & 247 &
\end{tabular}

\section{Badanie odporności smarów na utlenianie}

\section{Metoda PN-C-04143:1956}

Wytworzone bazowe smary: litowy i polimocznikowy, a także smary zawierające inhibitory utleniania przebadano w zakresie odporności na utlenianie według PN-C-04143:1956. Wyniki badań przedstawiono $\mathrm{w}$ tablicach 5 i 6 oraz na rysunku 4 .

Na podstawie uzyskanych wyników badań stwierdzono, że smary wytworzone z zastosowaniem zagęszczacza polimocznikowego charakteryzują się lepszą odpornością na utlenianie niż smary litowe. Dla smarów litowych najskuteczniejszym inhibitorem utlenienia okazały się dodatki typu fenolowego (A, B), a najmniej skutecznymi - dodatki typu: dialkiloditiofosforan cynku (D) i karbaminianu (F). Dla smarów

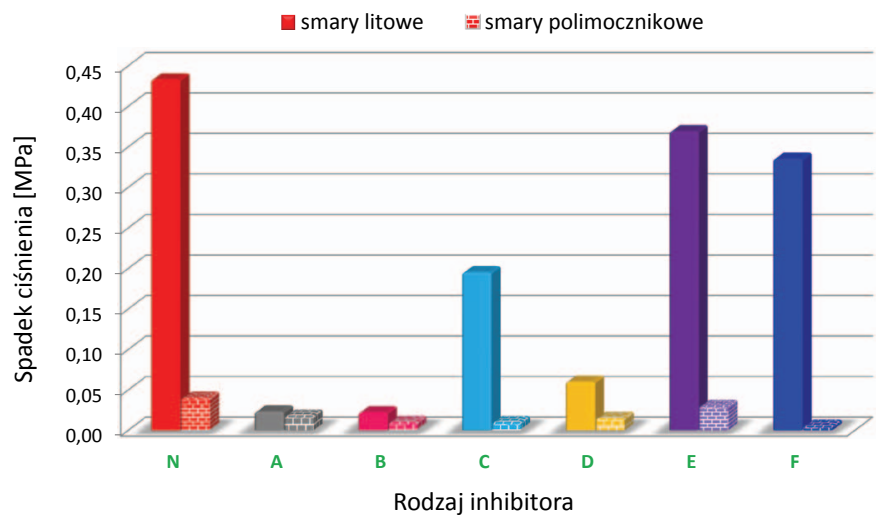

Rys. 1. Wpływ rodzaju zagęszczacza na odporność smarów na utlenianie według metody PN-C-04143:1956

Tablica 5. Odporność na utlenianie według metody PN-C-04143:1956 smarów litowych:

bazowego oraz zawierających $0,5 \%(\mathrm{~m} / \mathrm{m})$ inhibitora utleniania

\begin{tabular}{|c|c|c|c|c|c|c|c|}
\hline Numer próbki & TOLi0 & TOLi1 & TOLi2 & TOLi3 & TOLi4 & TOLi5 & TOLi6 \\
\hline Rodzaj inhibitora & N (brak) & A & B & C & D & E & F \\
\hline Utlenianie $100^{\circ} \mathrm{C} / 100 \mathrm{~h}$, spadek ciśnienia $[\mathrm{MPa}]$ & 0,433 & 0,023 & 0,022 & 0,195 & 0,060 & 0,369 & 0,335 \\
\hline
\end{tabular}

Tablica 6. Odporność na utlenianie według metody PN-C-04143:1956 smarów polimocznikowych: bazowego oraz zawierających $0,5 \%(\mathrm{~m} / \mathrm{m})$ inhibitora utleniania

\begin{tabular}{|c|c|c|c|c|c|c|c|}
\hline Numer próbki & TOPu0 & TOPu1 & TOPu2 & TOPu3 & TOPu4 & TOPu5 & TOPu6 \\
\hline Rodzaj inhibitora & N (brak) & A & B & C & D & E & F \\
\hline Utlenianie $100^{\circ} \mathrm{C} / 100 \mathrm{~h}$, spadek ciśnienia [MPa] & 0,040 & 0,018 & 0,010 & 0,010 & 0,015 & 0,030 & 0,005 \\
\hline
\end{tabular}


polimocznikowych najskuteczniejszym inhibitorem utlenienia był dodatek typu karbaminianu $(\mathrm{F})$.

\section{Zmodyfikowana metoda Petrooxy}

Wytworzone bazowe smary: litowy i polimocznikowy oraz smary zawierające inhibitory utleniania przebadano w zakresie odporności na utlenianie przy użyciu zmodyfikowanej metody Petrooxy, według PN-EN 16091:2011.
Wyniki badań przedstawiono w tablicach 7 i 8 oraz na rysunkach 5-8.

Na podstawie uzyskanych wyników badań stwierdzono, że smary wytworzone z zastosowaniem zagęszczacza polimocznikowego charakteryzują się lepszą odpornością na utlenianie niż smary litowe. W badaniu przeprowadzonym metodą Petrooxy zaobserwowano, że dla smarów litowych najskuteczniejszymi inhibitorami utlenienia okazały się dodatki typu feno-

Tablica 7. Odporność na utlenianie metodą Petrooxy smarów litowych:

bazowego oraz zawierających $0,5 \%(\mathrm{~m} / \mathrm{m})$ inhibitora utleniania w temperaturach $100 \mathrm{i} 140^{\circ} \mathrm{C}$

\begin{tabular}{|c|c|c|c|c|c|c|c|}
\hline Numer próbki & TOLi0 & TOLi1 & TOLi2 & TOLi3 & TOLi4 & TOLi5 & TOLi6 \\
\hline Rodzaj inhibitora & N (brak) & A & B & C & D & E & F \\
\hline Ciśnienie $800 \mathrm{kPa}$, temperatura $100^{\circ} \mathrm{C}[\mathrm{min}]$ & 170 & 2156 & 2402 & 827 & 616 & 163 & 150 \\
\hline Ciśnienie $800 \mathrm{kPa}$, temperatura $140^{\circ} \mathrm{C}[\mathrm{min}]$ & 32 & 193 & 145 & 61 & 48 & 31 & 31 \\
\hline
\end{tabular}

Tablica 8. Odporność na utlenianie metodą Petrooxy smarów polimocznikowych: bazowego oraz zawierających $0,5 \%(\mathrm{~m} / \mathrm{m})$ inhibitora utleniania w temperaturach 100 i $140^{\circ} \mathrm{C}$

\begin{tabular}{|c|c|c|c|c|c|c|c|}
\hline Numer próbki & TOPu0 & TOPu1 & TOPu2 & TOPu3 & TOPu4 & TOPu5 & TOPu6 \\
\hline Rodzaj inhibitora & N (brak) & A & B & C & D & E & F \\
\hline Ciśnienie $800 \mathrm{kPa}$, temperatura $100^{\circ} \mathrm{C}[\mathrm{min}]$ & 1259 & 2689 & 3261 & 3318 & 2997 & 1480 & 3244 \\
\hline Ciśnienie $800 \mathrm{kPa}$, temperatura $140^{\circ} \mathrm{C}[\mathrm{min}]$ & 454 & 520 & 528 & 807 & 773 & 512 & 692 \\
\hline
\end{tabular}

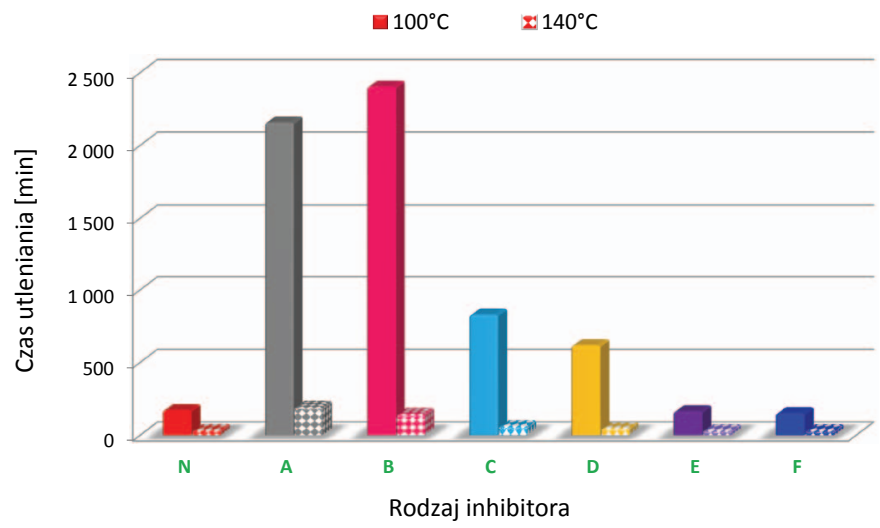

Rys. 2. Odporność na utlenianie metodą Petrooxy smarów litowych w temperaturach 100 i $140^{\circ} \mathrm{C}$

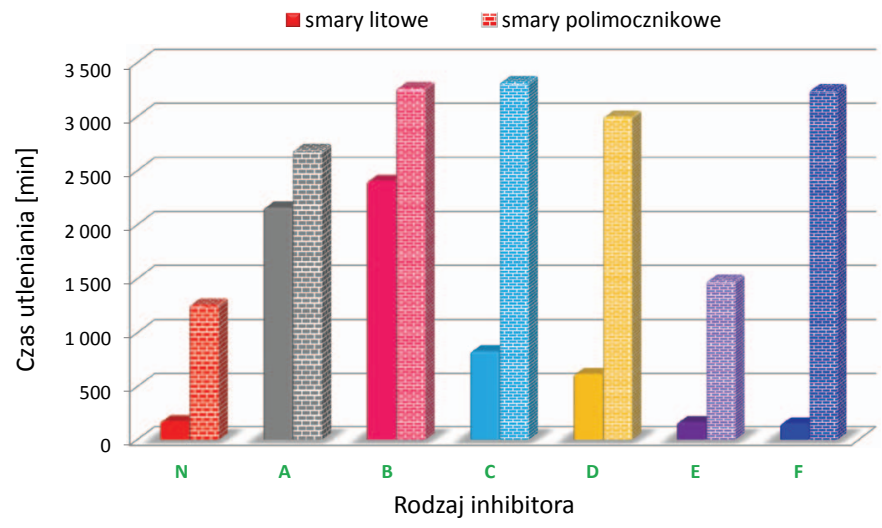

Rys. 4. Wpływ rodzaju zagęszczacza na odporność smarów na utlenianie metodą Petrooxy w temperaturze $100^{\circ} \mathrm{C}$

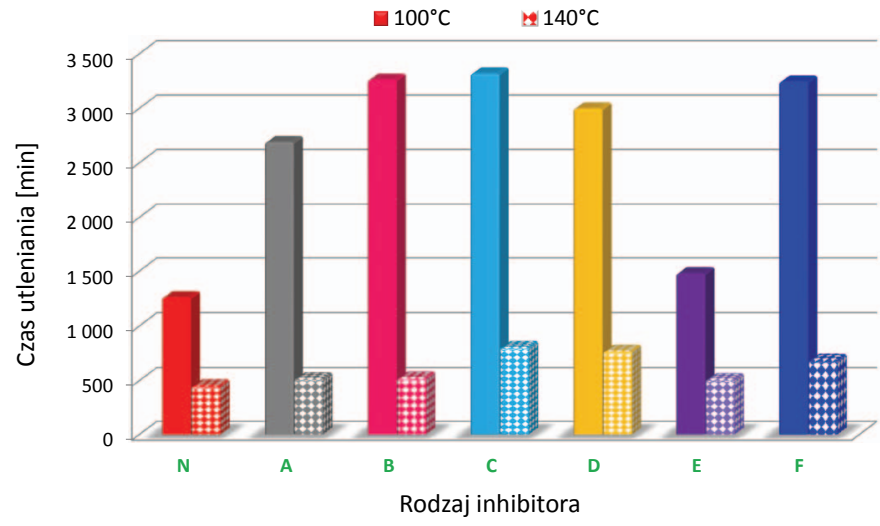

Rys. 3. Odporność na utlenianie metodą Petrooxy smarów polimocznikowych w temperaturach 100 i $140^{\circ} \mathrm{C}$

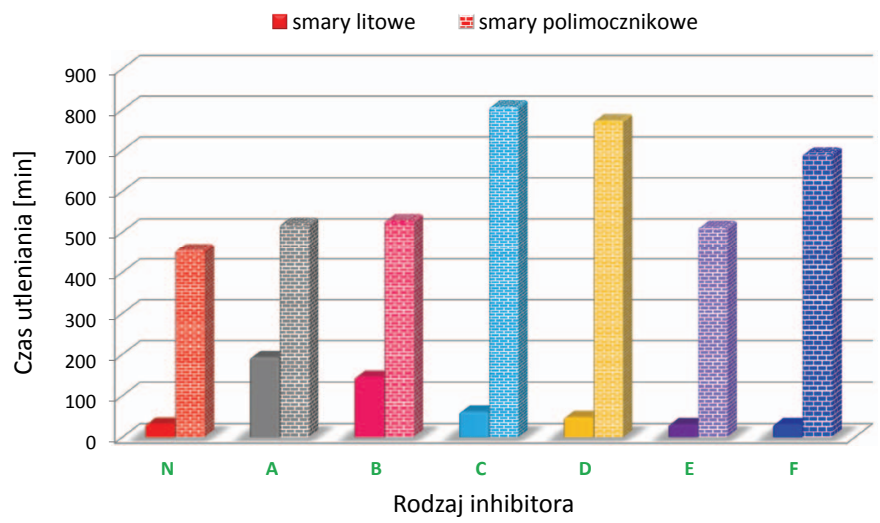

Rys. 5. Wpływ rodzaju zagęszczacza na odporność smarów na utlenianie metodą Petrooxy w temperaturze $140^{\circ} \mathrm{C}$ 
lowego (A, B), a najmniej skutecznym - dodatek typu karbaminianu (F). Dla smarów polimocznikowych najlepszym inhibitorem utlenienia był dodatek (C) typu aminowego, a naj- mniej skutecznym - dodatek (E) typu ZnDTP. Równocześnie stwierdzono, że podwyższenie temperatury badania ze $100^{\circ} \mathrm{C}$ do $140^{\circ} \mathrm{C}$ powoduje 3-4-krotny spadek odporności na utlenianie.

\section{Podsumowanie}

Przeprowadzono badania stabilności termooksydacyjnej smarów wytworzonych na bazie oleju o charakterze naftenowym, grupy V według API, zawierających jako zagęszczacze 12-hydroksystearynian litu lub polimocznik oraz wzbogaconych inhibitorami utleniania o różnym charakterze chemicznym w ilości $0,5 \%(\mathrm{~m} / \mathrm{m})$.

Badanie odporności na utlenianie smarów prowadzono według metody PN-C-04143:1956 przeznaczonej dla sma- rów oraz przy użyciu zmodyfikowanej metody Petrooxy według PN-EN 16091:2011.

Stabilność smarów plastycznych może być modyfikowana poprzez wprowadzenie odpowiednich przeciwutleniaczy, których dobór zależy od rodzaju zagęszczacza smaru plastycznego oraz temperatury pracy smaru. Zmodyfikowana metoda Petrooxy jest skutecznym narzędziem pozwalającym na badanie stabilności oksydacyjnej smarów plastycznych.

\section{Podsumowanie dla obu części}

Wyniki badań uzyskanych w obu metodach badawczych pozwoliły na stwierdzenie, że dla smarów litowych (wytworzonych na olejach bazowych zarówno o charakterze parafinowym, jak i naftenowym) najskuteczniejsze inhibitory utlenienia (z przebadanych) to dodatki fenolowe, natomiast najsłabszy jest inhibitor typu karbaminianu. Dodatek typu ZnDTP bardzo słabo poprawia odporność na utlenianie smarów litowych wytworzonych na bazie oleju o charakterze naftenowym.

Analizując wyników badań otrzymanych w obu metodach badawczych, można stwierdzić, że dla smarów polimoczni- kowych wytworzonych z użyciem oleju bazowego o charakterze parafinowym najskuteczniejszym (z przebadanych) inhibitorem utlenienia dla niższych temperatur pracy jest dodatek fenolowy (A), a dla wyższych temperatur - dodatek aminowy (C). Dla smarów polimocznikowych stosowanych w wyższych temperaturach najlepszym inhibitorem utlenienia (z przebadanych) jest dodatek aminowy (C). Najgorszym inhibitorem utlenienia dla smarów polimocznikowych (wytworzonych na olejach bazowych, zarówno o charakterze parafinowym, jak i naftenowym) okazał się dodatek typu ZnDTP.

Prosimy cytować jako: Nafta-Gaz 2017, nr 1, s. 49-53, DOI: 10.18668/NG.2017.01.06

Artykuł nadesłano do Redakcji 19.08.2016 r. Zatwierdzono do druku 11.10.2016 r.

Artykuł powstał na podstawie pracy statutowej pt. Badanie możliwości modyfikacji stabilności termooksydacyjnej smarów plastycznych - praca INiG - PIB na zlecenie MNiSW; nr zlecenia: 0007/TE/TO/15, nr archiwalny: DK-4100-7/15.

\section{Literatura}

[1] Skibińska A., Żółty M.: Badanie możliwości modyfikacji stabilności termooksydacyjnej olejów bazowych. Nafta-Gaz 2015, nr 5, s. 327-336.

[2] Trzaska E., Żółty M., Skibińska A.: Badanie stabilności termooksydacyjnej smarów plastycznych. Część 1: Smary na oleju o charakterze parafinowym. Nafta-Gaz 2016, nr 11, s. 984-991.

\section{Akty prawne i normatywne}

[3] PN-C-04143:1956 Przetwory naftowe - Smary stałe - Badanie odporności na utlenianie.

[4] PN-EN 16091:2011 Ciekle przetwory naftowe - Paliwa i mie-

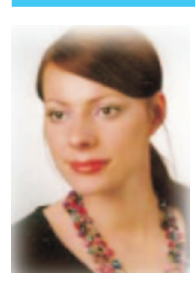

Mgr inż. Magdalena ŻÓŁTY

Specjalista badawczo-techniczny w Zakładzie Oceny Właściwości Eksploatacyjnych; kierownik Laboratorium Badań Właściwości Użytkowych.

Instytut Nafty i Gazu - Państwowy Instytut Badawczy ul. Lubicz 25 A, 31-503 Kraków

E-mail:magdalena.zolty@inig.pl szaniny ze średnich destylatów naftowych i estrów metylowych kwasów tluszczowych (FAME) - Oznaczanie stabilności oksydacyjnej metoda szybkiego utleniania w małej skali.

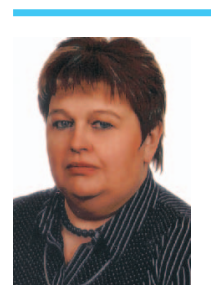

Mgr inż. Elżbieta TRZASKA

Kierownik Laboratorium Olejów, Środków Smarowych i Asfaltów w Zakładzie Olejów, Środków Smarowych i Asfaltów.

Instytut Nafty i Gazu - Państwowy Instytut Badawczy ul. Lubicz 25 A, 31-503 Kraków

E-mail: elzbieta.trzaska@inig.pl

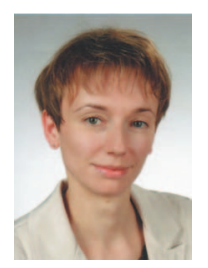

Mgr inż. Agnieszka SKIBIŃSKA

Asystent w Zakładzie Olejów, Środków Smarowych i Asfaltów.

Instytut Nafty i Gazu - Państwowy Instytut Badawczy ul. Lubicz 25 A

31-503 Kraków

E-mail:agnieszka.skibinska@inig.pl 